\title{
PROCEDIMENTOS DE MANUTENÇÃO PADRÃO PARA ATIVIDADES E SERVIÇOS EM ELETRICIDADE E SEU PAPEL NA PREVENÇÃO DE ACIDENTES DO TRABALHO.
}

\section{STANDARD MAINTENANCE PROCEDURES FOR ACTIVITIES AND SERVICES IN ELECTRICITY AND YOUR ROLE AT WORK ACCIDENTS PREVENTION.}

\author{
Daniel Ferreira Fernandes de Albuquerque ${ }^{1}$; Odilon Carreiro de Almeida Neto²; \\ ${ }^{1}$ Instituto de Educação Superior da Paraíba - IESP/FATEC PB - Cabedelo - PB - Brasil \\ daniel.albuquerque@ee.ufcg.edu.br \\ ${ }^{2}$ Instituto de Educação Superior da Paraíba - IESP/FATEC PB - Cabedelo - PB - Brasil \\ odilon@iesp.edu.br
}

\section{Resumo}

O presente trabalho tem o objetivo de analisar os procedimentos padrões de segurança em relação a serviços com eletricidade com o escopo de reduzir o alto índice de acidentes de trabalho. Quando há um ambiente de trabalho que envolve eletricidade direta ou indiretamente ou ainda em sua proximidade é necessário adotar medidas para que o risco não se torne um acidente. Os serviços que envolvem eletricidade são potenciais causadores de riscos ao trabalhador, o qual está sujeito quando opera com eletricidade, mesmo que se trate de instalação elétrica de baixa tensão. $O$ contato com o corpo e as partes energizadas de uma instalação elétrica de baixa tensão produz o chamado "choque elétrico", e se for de alta tensão, têm-se o "arco elétrico" que precede de contato, e em geral, leva à morte. Nesta conjuntura, a Norma Brasileira NR-10 tem o condão de adequar os procedimentos de trabalho, a formalização dos papéis e responsabilidades dos profissionais envolvidos, e a prática das medidas de controle dos riscos. Assim, este trabalho tem a finalidade de realizar uma revisão bibliográfica sobre a Norma Regulamentadora NR-10 e analisar e aplicar procedimentos padrões relacionando com o atual cenário de segurança no trabalho.

Palavras-chave: norma regulamentora 10; eeletricidade; procedimentos de trabalho. ANEEL.

\section{Introdução}

Os ambientes industriais são locais que, naturalmente, possuem um grande potencial de risco, pois são locais onde se desempenham diferentes tipos de atividades com bastante interação homem-máquina (empilhadeiras, prensas, pontes rolantes, esteiras, máquinas rotativas, etc) e com diferentes tipos de riscos (ergonômicos, acidentes, físicos, químicos).

Dentre todos os riscos existentes, os que envolve atividades de manutenção elétrica destacam-se pelo exorbitante número de acidentes laborais. $\mathrm{O}$ risco de acidentes por choque 
elétrico, apenas no ano de 2014, causou a morte de 57 pessoas no Brasil (ANEEL, 2015), além da ocorrência, no mesmo ano, de 836 acidentes registrados com terceiros envolvendo a rede elétrica e demais instalações no Brasil (ANEEL, 2015) com grandes efeitos de alto grau de nocividade aos acidentados.

Por esses indicadores e pela exigência natural da melhoria das condições de trabalho e da formação dos funcionários que trabalham na manutenção de equipamentos e máquinas elétricas, surge a necessidade da preparação de um conjunto de procedimentos e instruções técnicas e administrativas para se trabalhar na prevenção e, principalmente, na formação de funcionários mais preparados. Esses procedimentos são criados a partir das normas de segurança nacionais que norteam o assunto, junto com uma avaliação in loco dos riscos existentes na operação a ser desempenhada.

Neste sentido, pretende-se analisar rigorosamente os procedimentos de manutenção padrão para atividade e serviços de eletricidade, para que seja possível reduzir a zero a probabilidade de ocorrência de um evento perigoso com a gravidade da lesão, doença ou perda no ambiente de trabalho. É importante a análise e melhoramento do sistema pessoa/ máquina e da organização empresarial, além do desenvolvimento de competências adequadas para eliminar os acidentes potenciais e infortúnios.

Ao esmiuçar os aspectos relevantes dos procedimentos básicos para exercer qualquer atividade com eletricidade, extrai-se que a empresa em conjunto com os trabalhadores devem se adequar as orientações contidas nos regulamentos. A empresa deve manter os trabalhadores informados sobre os riscos a que estão expostos, adotar medidas preventivas e corretivas e promover ações de controle de riscos originados por outrem em suas instalações elétricas e oferecer, de imediato, quando cabível, denúncia aos órgãos competentes. Os trabalhadores devem zelar pela sua segurança e saúde e a de outras pessoas que possam ser afetadas por suas ações ou omissões no trabalho, responsabilizando-se junto com a empresa pelo cumprimento das disposições legais e regulamentares e comunicar, de imediato, ao responsável pela execução do serviço as situações que considerar de risco.

Portanto, as investigações dos acidentes mostram que a causa-raiz converge sempre para o descumprimento dos procedimentos de trabalho. Contribuem para esta conduta diversos aspectos culturais e organizacionais que dificultam a capacitação, o engajamento e a prática disciplinada das medidas de segurança. O presente trabalho tem objetivo de mostar a importância do cumprimento dos procedimentos básicos, além de em cada caso concreto, verificar possíveis outros riscos e consequente outros tipos de procedimentos para evitar que o risco torne-se efetivamente um acidente de trabalho. 


\section{Referencial Teórico}

Ao buscar entender a gênese dos acidentes do trabalho, partiu-se da ideia que existe uma Norma Regulamentadora, mas que ela não é efetivamente cumprida. A literatura especializada possibilitou a construção dos pilares teóricos, mostrado nesta seção, e, que sustentam as análises deste trabalho, para tanto está apresentado em um primeiro momento a segurança do trabalho em sua relação com a eletricidade, desde a caracterização e prescrição contidas na norma regulamentadora 10 até as medidas de controle dos riscos elétricos. $\mathrm{O}$ aprofundamento do estudo realizado, a partir da norma reguladora e demais regulamentos, orientam a melhor forma de proceder com atividades que envolve eletricidade. As pretensas "respostas" apresentadas aos questionamentos que constituem esse diálogo serão desenvolvidas no texto.

\subsection{Segurança do trabalho com eletricidade}

Dentre todos os riscos existentes nas atividades de manutenção elétrica, a maior preocupação sobre segurança com esse tipo de serviço é em relação ao risco de choque elétrico, o qual ocorre quando a pessoa ao entrar em contato com parte energizada, torna-se segmento do circuito elétrico, por onde a corrente elétrica irá fluir pelo seu corpo, podendo causar diversar reações como a parada respiratória, fibrilação ventricular, sendo as principais:

- Queimaduras: dependendo da intensidade da corrente que fluirá pelo corpo é possível ocorrer queimaduras profundas que acometam toda a derme e atinga os tecidos subcutâneos, destruindo totalmente os nervos e até a musculatura e estrutura óssea do acidentado. Isso se dá devido ao efeito Joule, em que a energia elétrica é convertida em energia térmica ao passar por uma resistência, elevando a temperatura a pontos críticos.

- Tetanização: paralisão muscular, que devido ao choque elétrico, acontece a forte contração dos músculos ocorrendo então a paralisia muscular. Esse tipo de reação pode causar o "travamento" do acidentado ao ponto de choque, já que ele não consegue comandar sua musculatura e soltar o ponto energizado, ou até mesmo paradas cardíacas, devido a tetanização das fibras musculares do tecido do coração. 
Existem também riscos adicionais que devem ser avaliados antes da realização de atividades envolvendo eletricidade, pois podem surgir potenciais danos ao empregado, como por exemplo, o risco de incêndio ou explosão em ambientes em que sua atmosfera possua a mistura de oxigênio e gás combustível numa determinada proporção que uma faísca ou qualquer outra fonte de ignição fará com que essa mistura se inflame. Além dos riscos de acidentes em trabalhos em alturas ou com locais confinados ou até mesmo com alta taxa de umidade relativa do ar que pode ocasionar arcos elétricos com risco de choque elétrico.

Neste contexto, deve-se adotar procedimentos, ferramentas e medidas de segurança apropriadas para trabalhar com eletricidade e assim, garantir a segurança e a integridade dos trabalhadores. As medidas de segurança devem ser específicas para cada tipo de atividade. Profissionais capacitados para realizar o trabalho com eletricidade são essenciais para que as medidas de segurança sejam aplicadas da forma correta. Também é importante que a instalação elétrica seja inspecionada e mantida em boas condições, uma vez que uma instalação degradada acarreta risco mais elevado no momento de realizar qualquer intervenção. É possível a definição de três pilares para trabalhar de maneira segura com a eletricidade: Instalações, ferramental e equipamentos de segurança apropriados; Procedimentos de trabalho, administrativos e técnicos, adequados; Profissionais capacitados e autorizados; (SANTOS JR., 2013)

\subsection{Norma regulamentadora 10}

A NR10 é uma norma regulamentadora estabelecida pelo Ministério do Trabalho e Emprego que foi criada especificamente para atender profissionais que atuam com serviços ligados à área elétrica, tais serviços são considerados de alto risco devido a elevada ocorrência de graves acidentes envolvendo este tipo de atividade. Seu principal objetivo é proteger e diminuir acidentes graves, principalmente, os fatais, através de equipes e profissionais devidamente qualificados e treinados, os quais devem estar sempre atentos ao cumprimento de todas as etapadas estabelecidas na norma para evitar danos permanentes à saúde durante o exercício do trabalho em instalações elétrica de baixa, média ou alta tensão.

A NR10 estabelece as condições mínimas visando a implementação de medidas de controle e sistemas preventivos, em seu primeiro capítulo, a intenção de prevenir os acidentes de trabalho. Aplica-se às empresas de energia, geradoras, transmissoras e distribuidoras, bem como as demais instalações elétricas que se enquadram na fase de consumo, como indústrias, 
comercio, empresas publicas, etc. Limita a sua aplicação às instalações com tensão elétrica superior a $50 \mathrm{~V}$ em corrente alternada ou $120 \mathrm{~V}$ em corrente continua.

As responsabilidades atribuídas às empresas e aos trabalhadores não estão limitadas somente à NR-10, mas também pela Constituição Federal, Consolidação das Leis do Trabalho (CLT) e, pelos Códigos Civil e Criminal. A NR-10 estabelece que as responsabilidades quanto ao seu cumprimento sejam solidárias aos contratantes e contratados. Para os contratantes abrange a responsabilidade técnica da instalação e a integridade física dos trabalhadores. Inclui a informação dos riscos a que os trabalhadores estão expostos, assim como procedimentos e medidas de controle a serem adotados. Aos trabalhadores cabe zelar pela sua segurança e saúde, e a de outras pessoas que possam ser afetadas por suas ações, responsabilizar-se junto com a empresa pelo cumprimento das disposições legais, e comunicar ao responsável pela execução do serviço as situações que considerar de risco (BARROS, 2010).

Em seu texto há clara distinção entre os termos risco e perigo, sendo que perigo é a condição de risco com probabilidade de causar lesões ou danos à saúde das pessoas por ausência de medidas de controle, e o risco é a capacidade de causar lesões ou danos à saúde. O profissional que atua em instalações elétricas deve conhecer os riscos da exposição, bem como seus procedimentos e medidas preventivas. (SANTOS JR., 2013). Portanto, é inerente as atividade elétricas o risco, entretanto, para que estes riscos não se tornem causadores de acidentes de trabalho é preciso que a norma e demais procedimentos extras - identificados em cada caso concreto- sejam devidamente cumpridos.

Os principais objetivos da NR-10 são a preservação da segurança e da saúde dos trabalhadores, que podem ser afetadas pelos riscos elétricos e também por outros riscos adicionais. Ela estabelece que devam também ser adotadas medidas preventivas para controle dos riscos adicionais, especialmente quanto à altura, confinamento, campos eletromagnéticos, explosividade, umidade, poeira, fauna, flora e outros agravantes.

O trabalhador que atua em instalações elétricas ou em suas proximidades deve conhecer não só os riscos a que esta exposto, como também os procedimentos e as medidas para evitá-los. Para controlar os riscos devem ser desenvolvidas medidas de controle coletivas, administrativas e técnicas, e, por fim, de controle individuais. A NR10 no seu artigo 10.2.8.2 orienta que a desenergização elétrica é, prioritariamente, a medida de proteção coletiva a ser adotada e na sua impossibilidade o emprego de tensão de segurança, seguindo essa orientação da norma, o tema de desenergização elétrica receberá atenção especial e 
prioridade nos procedimentos a serem criados, para isso é importante conhecer mais detalhes nas etapas da desenergização.

\subsection{Medidas de controle dos riscos elétricos}

De acordo com a NR-10, a principal medida de prevenção coletiva é a desenergização elétrica, em que é preciso realizar um sequência de atividades para poder considerarmos considerar desenergizadas as instalações elétricas liberadas para trabalho, obedecendo a sequência abaixo:

- Seccionamento:

Consiste no ato de separação ou descontinuidade elétrica do circuito, através de dispositivos adequados para tal função (disjuntores, seccionadores, interruptor), ou seja, é feita a interrupção da alimentação de parte de uma instalação elétrica, eliminando a passagem de corrente elétrica no local a ser trabalhado.

- Impedimento de reenergização:

Ação de impedir, de modo efetivo, que haja a reenergização involuntária ou acidental do circuito (acionamento ou religamento automático) em que se está sendo trabalhado, utilzando-se bloqueios físicos como cadeados, ou travas mecânicas com chave para sua abertura, que só poderá se aberto quando o serviço tiver sido concluído sem o risco de contato da parte energizada por nenhum trabalhador.

- Constatação da ausência de tensão:

Nessa etapa, é feita a verificação da ausência de tensão no circuito, utilizando um multímetro em estado adequado de uso. É importante certificar-se sobre o seu correto funcionamento realizando o teste energizado-desenergizado-energizado, onde é testado o multímetro em uma fonte energizada conhecida (numa faixa de tensão aproximada do circuito onde vai ser realizado o serviço), em seguida, verifica-se a ausência de tensão no circuito que foi bloqueado, e por fim, testa o dispositivo de medição novamente na fonte energizada conhecida, para garantir assim, a conformidade do funcionamento do multímetro.

- Instalação de aterramento temporário

$\mathrm{O}$ aterramento temporário é instalado nos condutores do circuito para o sistema de aterramento do mesmo, para garantir a equipotencialidade das fases do local de trabalho e para evitar acidentes devido a energizações indevidas. $\mathrm{O}$ aterramento temporário deve ser instalado primeiramente no terra e ao neutro do sistema, quando houver, e as demais partes condutoras deverão ser conectadas as garras nos condutores fase, previamente desligados. Os 
possíveis pontos de fluxo de corrente elétrica deverão ser determinados através da realização da Análise Preliminar de Risco (APR).

- Proteção dos elementos energizados existentes na zona controlada;

A zona controlada é a área em torno da parte condutora energizada de dimensões estabelecidas de acordo com os níveis de tensão, cuja aproximação só é permitida com profissionais autorizados. É recomendada a utilização de obstáculos e anteparos, para impedir o contato involuntário com partes energizadas como cones combinados com fitas de sinalização (zebrada), grades colocando a parte energizada fora do alcance de pessoas sem autorização. Os elementos a serem protegidos devem ser identificados por meio da APR.

- Instalação da sinalização de impedimento de reenergização;

A sinalização é um Equipamento de Proteção Coletiva (EPC), em que são utilizados cartões de identificação dos funcionários nos seus respectivos bloqueios e placas com função de alertar, advertir e orientar as pessoas a respeito dos riscos e perigos no local, além de proibir o acesso de pessoas não autorizadas àquela atividade desempenhada. Os dispositivos a serem sinalizados devem ser determinados por meio da APR.

A NR 10 também cita medidas padrões para a reenergização do circuito desenergizado. São elas:

- Retirada de ferramentas, utensílios e equipamento;

Para garantir a integrida das pessoas em serviço e do sistema elétrico do qual está sendo trabalhado, recomenda-se antes de energizar retirar todas as ferramentas e utensílios para que no momento da energização não hajam curtos circuitos nem risco de contato a parte energizada através das ferramentas e equipamentos ligados ao circuito energizado. Deixar ligado apenas o aterramento temporário após essa etapa.

- Retirada da zona controlada de todos os trabalhadores não envolvidos no processo de reenergização;

É de responsabilidade do manutentor responsável pela intervenção, certificar-se de que todos os trabalhadores não envolvidos nos procedimentos de reenergização estejam fora da zona controlada antes de efetuar os próximos passos da sequência.

- Remoção do aterramento temporário, da equipotencialização e das proteções adicionais;

Retirar o aterramento para evitar que ao fazer o religamento, ocorra um curto circuito, danificando os dispositivos e fios do sistema.

- Remoção da sinalização de bloqueio e impedimento de reenergização;

- Destravamento, se houver, e religamento dos dispositivos de seccionamento; 
As medidas de desenergização e reenergização, ampliadas ou eliminadas, deve sempre levar em consideração as peculiaridades de cada situação, sempre procedida por profissional legalmente habilitado, autorizado e mediante justificativa técnica previamente formalizada, para que não seja criada uma situação de risco aos empregados e terceiros.

\subsection{Procedimentos de trabalho}

A NR 10 impõe aos estabelecimentos com carga instalada acima de $75 \mathrm{~kW}$ a necessidade de constituir e manter o Prontuário das Instalações Elétricas, contendo nessa documentação o conjunto de procedimentos e instruções técnicas e administrativas de segurança e saúde.

O procedimento de trabalho orienta o funcionário a realizar uma atividade de forma uniforme, sem improvisos e sem ajustes que comprometam a segurança no seu trabalho, de modo que pessoas diferentes realizem a tarefa de maneira similar, atingido resultados previstos. A NR-10 estabelece que os serviços com eletricidade devam ser planejados e realizados conforme procedimentos de trabalho específicos e devem conter no mínimo, objetivo, campo de aplicação, base técnica, competências e responsabilidades, disposições gerais, medidas de controle e orientações finais.

Os procedimentos devem ser criados e assinados por profissionais autorizados (com qualificação ou capacitação e os profisionais habilitados com anuência formal da empresa). Não existe um formato específico ou padrão para elaboração de um procedimento, porém recomenda-se que eles sejam de fácil leitura (com linguagem mais simples possível e sem temos extremamente técnicos), objetivos (com frases curtas e diretas, sem redundâncias ou ambiguidades) .

Os procedimentos podem ser básicos ou específicos. Os básicos são aqueles que dão base e atendem várias atividades específicas, são exemplos clássicos desse tipo de procedimento a desenergização e energização.Os procedimentos específicos possuem determinações particulares, no caso de atividades de alta tensão é necessário dois técnicos habilitados e capacitados pela NR 10 e autorizados, e os trabalhadores deverão ter curso específico em Sistemas Elétricos de Potência (SEP). Ou seja, são criados especificamente para uma tarefa bem definida. 


\subsubsection{Análise de risco}

A Norma Regulamentadora 10 estabelece que deve anteceder a qualquer intervenção elétrica a elaboração de uma análise de risco para prever e prevenir possíveis acidentes. É imprescindível que, antes do início de qualquer procedimento, seja possível atestar um ambiente de risco tolerável. Risco tolerável é aquele que foi reduzido a um nível tolerável pela organização com relação as suas obrigações legais e sua política de saúde e segurança. $O$ desfech/o de uma avaliação de risco deve ser o inventário de ações, com prioridades, para elaborar, manter ou melhorar os controles.

Assim, a análise de risco deve ser feita preliminarmente a execução da atividade, para que o estudo antecipado e detalhado de todas as fases do trabalho seja capaz de detectar os possíveis problemas que poderão acontecer durante a execução. Após detectado os possíveis acidentes e problemas, devem ser adotadas medidas de controle e neutralização, essas medidas devem envolver toda equipe, criando um ambiente de trabalho seguro.Uma análise efeciente deve tomar como referência o PPRA, check list, formulários e demais documentos aptos a garantir a segurança.

Uma eficaz análise de risco preliminar deve conter os responsáveis pela aplicação, a data, nome da empresa, tarefa a ser executada, os riscos do trabalho detalhadamente, equipamentos de proteção individual e coletivo. É importante também listar os equipamentos usados durante o trabalho, pois cada equipamento gera um risco específico, e por menor que pareça, merece atenção e deve ser listado.Por fim, deve atentar-se para as normas de segurança correlacionando com cada etapa do trabalho que irá ser executado. A prevenção de risco deve ser periodicamente revista e a cada revisão alterada a ordem numérica da análise prévia.

Os resultados da avaliação devem ser coletados e registrados em uma planilha destinada a organizar e facilitar a análise, a qual deve conter também a recomendação das ações para controle dos riscos apurados considerando a necessidade de equipamentos de proteção coletiva e individual, ferramentas e equipamentos especiais, e outras medidas de proteção. Grande parte das medidas de controle de risco não resulta de cálculos sofisticados, mas da visão holística da segurança, conhecimento sobre falhas humanas, sinalização, organização, limpeza e boas práticas de trabalho (CARDELLA, 1999). 


\section{Estudo de caso}

Diante do cenário transparecido em que o ambiente de trabalho que envolve serviços e atividade com eletricidade oferece alto risco de acidente, é importante analisar o procedimento básico de uma empresa que possua uma equipe de manutenção elétrica dividida em três turnos, os quais são autorizados a realizar a manutenção dos dispositivos elétricos que acionam linhas de prensas na tensão máxima de $440 \mathrm{~V}$, sendo não autorizada a manutenção das cabines elétricas das subestações elétricas da planta ou de qualquer dispositivo em alta tensão (acima de 1000V).

À vista disso, foram criados procedimentos básicos em consonância com os requisitos regulamentares e legislações aplicáveis para tornar este procedimento seguro. Inicialmente, deve-se estabelecer o objetivo e campo de aplicação para minimizar a exposição aos riscos elétricos e ter como referência ABNT ISO 14001:2004, OHSAS 18001:2007, NR 10 Ministério do Trabalho, ABNT NBR 5410:2004 - Instalações Elétricas de Baixa Tensão, ABNT NBR 14039:2003 - Instalações elétricas de média tensão 1.0KV a 36.2KV, ABNT NBR 5460:1992 - Sistemas Elétricos de Potência.

A responsabilidade de tornar a empresa um lugar sem potencial de riscos de acidentes é necessário a atuação em conjunto de todos os depatamentos e equipes da empresa. $\mathrm{O}$ Departamento de Manutenção Predial e Instalações assegurar que os funcionários, terceiros e contratados envolvidos em atividades em sistemas elétricos sigam os requisitos este procedimento, entendendo o escopo do programa e os perigos associados com o trabalho que executam, bem como garantir a existência de número suficiente de funcionários treinados e disponíveis para realizar o trabalho, assim como a documentação de treinamento disponível. A Equipe de Manutenção e Empresas Prestadoras de Serviços são responsáveis por seguir este procedimento, cumprir o treinamento requerido, utilizar e manter em condições plenas de uso, todo equipamento de proteção individual (EPI) e equipamentos de proteção coletiva (EPC).

Já o Setor de Segurança do Trabalho, Saúde e Meio Ambiente deve realizar as inspeções de segurança do trabalho e meio ambiente para as atividades relacionadas a manutenção e operação de sistemas elétrico, relatar as situações de perigos e riscos de acidentes e de possíveis impactos ambientais. E se, durante a inspeção, constatar risco grave e iminente para a ocorrência de acidentes, interditar a atividade, máquina ou sistema, comunicando imediatamente à chefia responsável. Sempre que possível e necessário, proceder com uma análise preliminar de riscos. 
Antes do início da atividade, deve-se obter autorização para instalar, operar ou reparar instalações elétricas, colaboradores que tenham estado de saúde compatível, e anualmente devem ser reavaliados. Devem possuir treinamento específico sobre os riscos decorrentes do emprego da energia elétrica, conforme disposto do Anexo II da NR-10 e demais cursos complementares de capacitação. A autorização será dividida em quatro níveis, conforme nível de tensão do sistema elétrico, e o tipo de atividade desenvolvida.

Todos os profissionais envolvidos, executantes ou autorizadores, deverão ser formalmente capacitados e autorizados pela empresa e devem possuir Atestado de Saúde Ocupacional (ASO) constando os exames em conformidade com o PCMSO, assegurando que estejam aptos a executar trabalhos com eletricidade. A vestimenta a ser utilizada pelo trabalhador devem estar adequadas a classificação de risco do Painel de Distribuição Elétrica ou SEP. Todo painel de Distribuição Elétrica deve possuir a Classe de Risco Identificado na porta de acesso do Painel. Em todas as cabines elétricas, deve estar disponível diagrama Unifilar com a respectiva classificação de risco para cada dispositivo de manobra do SEP. Deve ser mantido e atualizado um controle de classificação de risco, contendo o código de identificação do Painel Elétrico, classe de risco, nível de Exposição (cal/cm²) e Mínimo de Proteção da Roupa (ATPV).

$\mathrm{Na}$ execução de atividades, como a empresa funciona em três turnos, em cada turno deve ter, no mínimo, dois trabalhadores autorizados. É indispensável que haja uma orientação acerca das tensões que serão manuseadas pelos trabalhadores. No caso especifico, a manutenção dos dispositivos elétricos que acionam linhas de prensas deverão ter a tensão máxima de $440 \mathrm{~V}$. É proibida e não autorizada a manutenção das cabines elétricas das subestações elétricas da planta ou de qualquer dispositivo em alta tensão (acima de 1000V). Portanto, ressalta-se que apesar de tratar-se de serviços com eletricidade, niveis diferentes de tensõs demandam procedimentos preventivos e corretivos especificos.

Por fim, a desenergização de instalações elétricas deve ser seccionada por dispositivo de manobra, como disjuntores e chaves seccionadoras e realizar a constatação de ausência de tensão. Procedendo-se com o bloqueio por dispositivo de segurança, instalação de aterramento temporário com equipotencialização dos condutores dos circuitos, para sistemas AT, instalação de Sinalização de impedimento de reenergização. O Bloqueio de Segurança só pode ser removido pelo responsável pelo bloqueio. Se houver necessidade de remoção do bloqueio, esta só poderá ocorrer após comunicação do Departamento de Segurança do Trabalho, e dos responsáveis pelo Setor, seguindo procedimento de Bloqueio de Energias Perigosas. 
Para energizar deve-se fazer uma verificação prévia da instalação e das cargas ligadas a ela, garantindo a ausência de ferramentas, utensílios, equipamentos ou partes condutoras expostas e sem proteção. Retirar as cabines elétricas de todos os trabalhadores não envolvidos no processo de reenergização, do aterramento temporário, bloqueio de segurança, ealização da manobra de energizaçãoe a verificação do nível de tensão em todas as fases.

\subsection{Procedimento específico - Substituição de disjuntor monofásico}

Aplicando na prática o que a norma nos recomenda, inicia-se a preparação do procedimento específico de manutenção para a atividade de substituição de disjuntor monopolar com defeito, realizando a análise de risco da atividade com o auxílio da ferramenta de Análise Preliminar de Risco (APR), em que levantamos os tipos de EPIs, as ferramentas que serão usadas, a matriz para análise de risco em que levantamos que a severidade da consequência de um acidente é crítica e que a probabilidade de ocorrência de acidente é remota, resultando assim num nível de risco marginal, do qual serão necessárias medidas de contenção para evitar o acidente, por isso, criaremos o procedimento específico como uma das medidas de segurança.

No procedimento, colocamos o nome da atividade, as observações importantes (sendo uma delas a leitura do procedimento básico de atividades com equipamentos elétricos e eletricidade em geral), quais EPIs serão necessários (descritos com símbolos), a frequência, o tempo e quantas pessoas são necessárias para realizar a atividade. Em seguida, damos início a descrição das atividades em si, descrevendo-as com texto de fácil entendimento, direto e com representação de fotos.

No primeiro passo, é feita a localização do disjuntor ou chave seccionadora que alimenta o disjuntor a ser trocado, desliga-se os dois dijuntores. No segundo passo, indica-se inserir a proteção dos elementos energizados existentes na zona controlada, com material apropriado, para evitar choques involuntários durante a atividade (Figura 01).

Figura 01: Inserção de proteção nas áreas energizadas.

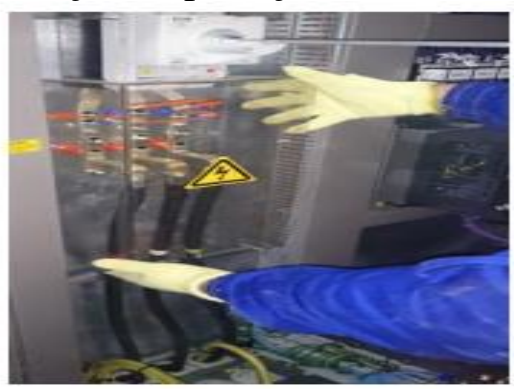

Fonte: Elaborada pelo autor, 2016 
No terceiro passo, orienta-se a instalar o dispositivo de bloqueio de religamento do disjuntor, travando-o com o cadeado junto da identificação do manutentor em atividade e instrução para não retirar bloqueio (Figura 02).

Figura 02: Inserção de dispositivo de bloqueio do disjuntor com cadeado e sinalização.

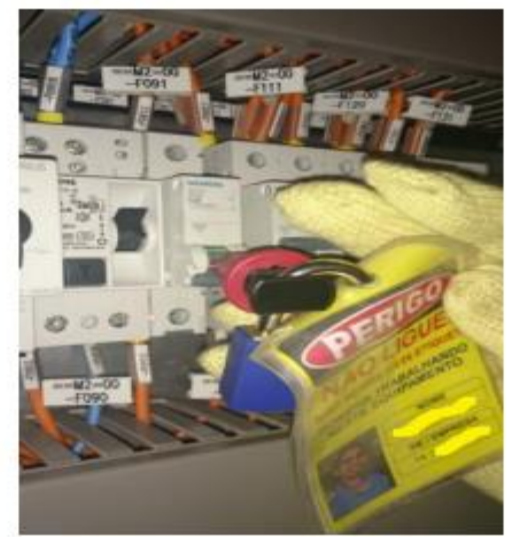

Fonte: Elaborada pelo autor, 2016

Em seguida, no quarto passo, é feita constatação da ausência de tensão, usando multímetro adequado e em bom estado (pilhas e faixa de tensão adequadas e em correto funcionamento), é importante realizar o teste do multímetro, medindo-se em um local que haja tensão conhecida, depois medir no local desligado e depois confirmar o funcionamento do multímetro medido-se novamente em local que haja tensão, para ter uma maior garantia de seu correto funcionamento.

Instala-se então aterramento temporário com equipotencialização dos condutores dos circuitos (colocar antes da entrada da alimentação do disjuntor a ser trocado), em seguida retira-se os cabos elétricos do disjuntor defeituoso, removendo-o do painel. Acrescenta-se no oitavo passo, o novo disjuntor fixando no painel e em seguida reinstala-se os fios de acordo com esquema elétrico.

Iniciando-se o processo de reenergização, são retiradas as ferramentas, utensílios e equipamentos utilizados na atividade guardando-os em local apropriado. Afastam-se todos trabalhadores não envolvidos no processo de reenergização e, por fim, remove-se o aterramento provisório.

Seguindo esses passos, agora é possível retirar o dispositivo de bloqueio do disjuntor com o cadeado de bloqueio com segurança, para assim poder realizar o religamento da energia no novo disjuntor (o procedimento completo, com imagens e mais detalhes, é encontrado em anexo). 


\section{Conclusão}

Os procedimentos estabelecidos na NR10 e demais legislações e regulamentos devem ser rigoramente cumpridos, entretanto, tratam-se de procedimentos básicos, pois em cada atividade que envolva eletricicidade deve-se proceder também com procedimentos extras específicos. Todos os riscos devem ser avaliados com a ajuda de um profissional qualificado, para que seja estabelecido, passo a passo, os procedimentos a serem adotados.O profissional legalmente habilitado para exercer determinada atividade ligada a eletricidade providenciará os materiais adequeados de apoio, examinará a análise prévia de risco, verificará se o local está limpo e iluminado, não utilizará anéis, relógios e demais adornos, enfim, realizará todos os procedimentos cabíveis para eliminar qualquer mínimo risco de acidente de trabalho.

É visível as inúmeras vantagens da padronização das atividades de manutenção pelo ponto de vista da segurança e também pelo fator econômico - importante em qualquer atividade desempenhada na atualidade -, pois através dos procedimentos é possível realizar a tarefa de forma planejada, estruturada, sem retrabalhos ou perda de tempo por falta de material. O procedimento especifica quais ferramentas e materiais serão necessários, qual a quantidade de manutentores ideal, além do que, os gastos decorrentes de um acidente do trabalho, como pagamento de benefício e danos, são bastante dispendiosos.

Apesar da melhor medida ser sempre previnir, na ocorrência de um eventual acidente, a empresa e os empregados devem ter condições de procedecer com os primeiros socorros e com o atendimento médico com os envolvidos no acidente. Principalmente com a criação e implantação da Norma Regulamentadora NR10, muitos acidentes e práticas equivocadas com relação ao manuseio de sistemas elétricas foram suprimidos, elevando a eficiência dos trabalhos e ao aumento da segurança dos profissionais da área, além de tornálos mais aptos e valorizados no mercado de trabalho.

Conclui-se, portanto, que a NR10 não é somente uma norma para ser aplicada na indústria de grande porte, mas sim um conceito de segurança que deve ser aplicado pelo profissional em todas as suas atividades. Esta norma em consonância com todas as normas reguladoras implementadas pelo Ministério de Trabalho e Emprego e demais referências são basilares para que haja um ambiente de trabalho seguro, dessarte, a empresa e os empregados devem ser rigorosos na aplicação dos procedimentos estabelecidos para que o ambiente de trabalho não seja um pontencial causador de danos ao trabalhador. 


\begin{abstract}
This study aims to analyze the safety standards procedures for services on electricity with the scope of reducing the high rate of accidents. When there is a work environment that involves electricity directly or indirectly or in its proximity is necessary to adopt actions so the risk does not become an accident. Services involving electricity are causing potential risk to the employee, which is subject when it operates with electricity, even in the case of low voltage electrical installation. The contact with the body and energized parts of an electrical installation of low voltage produces the so-called "electric shock", and if it's a high voltage installation, exist the electric arc that precedes contact, and generally leads to death. At this juncture, the Brazilian Standard NR-10 has the power to adjust the working procedures, the formalization of the roles and responsibilities of the professionals involved, and the practice of risk control countermeasures. Therefore, this work aims to conduct a literature review on the Regulatory Standard NR-10, analyzing and applying standard procedures relating to the current security scenario at work.
\end{abstract}

Keywords: Regulatory Standard NR-10. Electricity. Working procedure. ANEEL.

\title{
Referências
}

BARROS, Benjamim Ferreira de, et all. NR-10 Norma Regulamentadora de

Segurança em Instalações e Serviços de Eletricidade: Guia Prático de Análise e Aplicação. $1^{\text {a }}$ Edição. São Paulo: Erica, 2010.

CARDELLA, Benedito. Segurança dtrabalho e prevenção de acidentes. São Paulo: Atlas, 1999.

CARVALHO, José Otávio. A Indústria do Cimento e a Infraestrutura no Brasil. Disponível em: http://www.senado.gov.br/sf/comissoes/ci/ap/ AP20090511_joseotaviocarvalho.pdf Acesso em: 7 de janeiro de 2016.

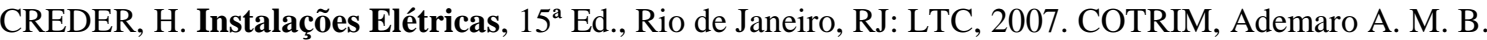
Instalações Elétricas. $4^{\mathrm{a}}$ Edição. São Paulo: Pearson Prentice Hall, 2003.

SANTOS JR., Joubert Rodrigues dos, NR-10 Segurança em Eletricidade, uma Visão Prática. São Paulo: Érica, 2013. 


\section{Apêndices}

Figura 03: Página 01 do procedimento específico de troca de disjuntor.

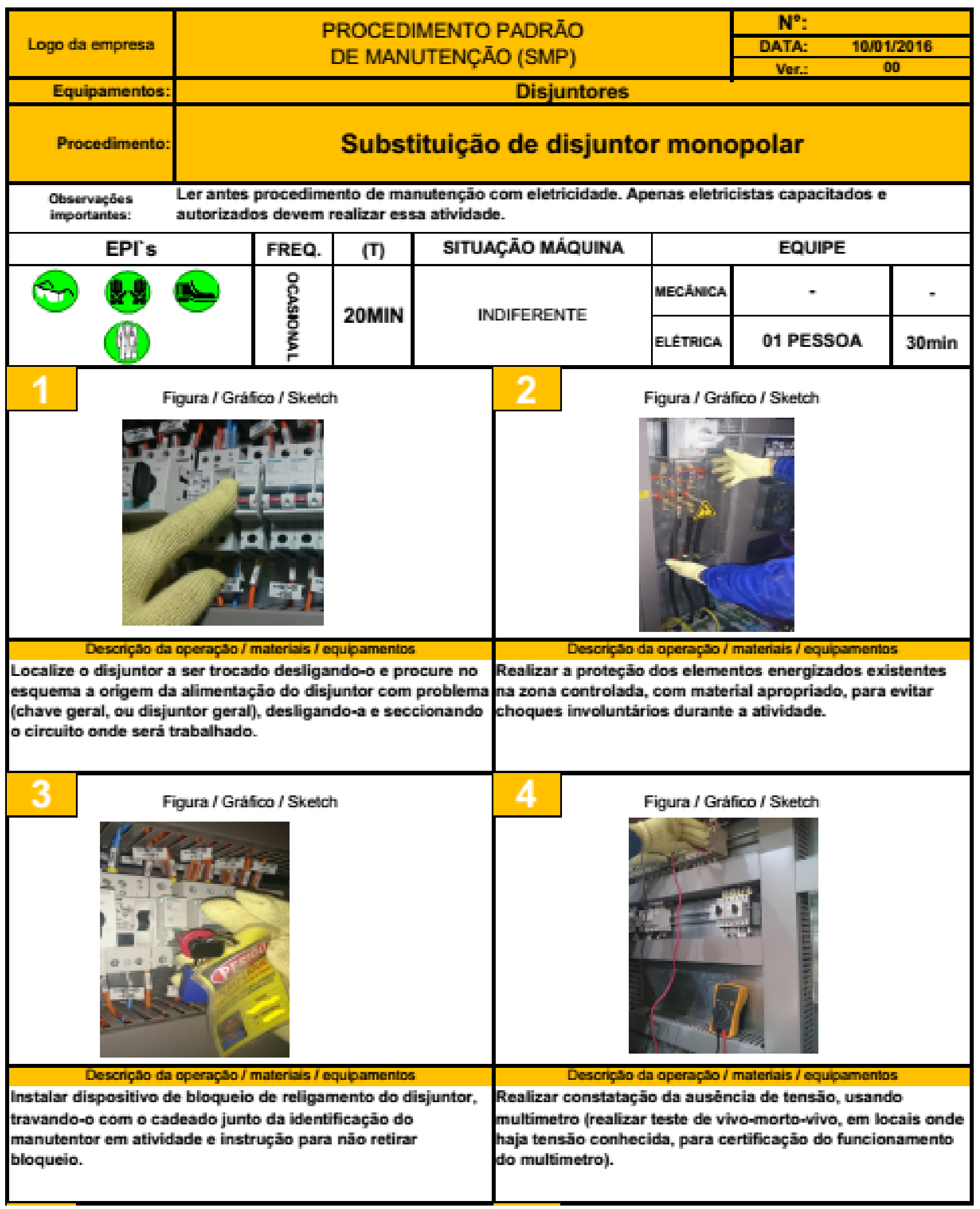

Fonte: Elaborada pelo autor, 2016. 
Figura 04: Página 02 do procedimento específico de troca de disjuntor.

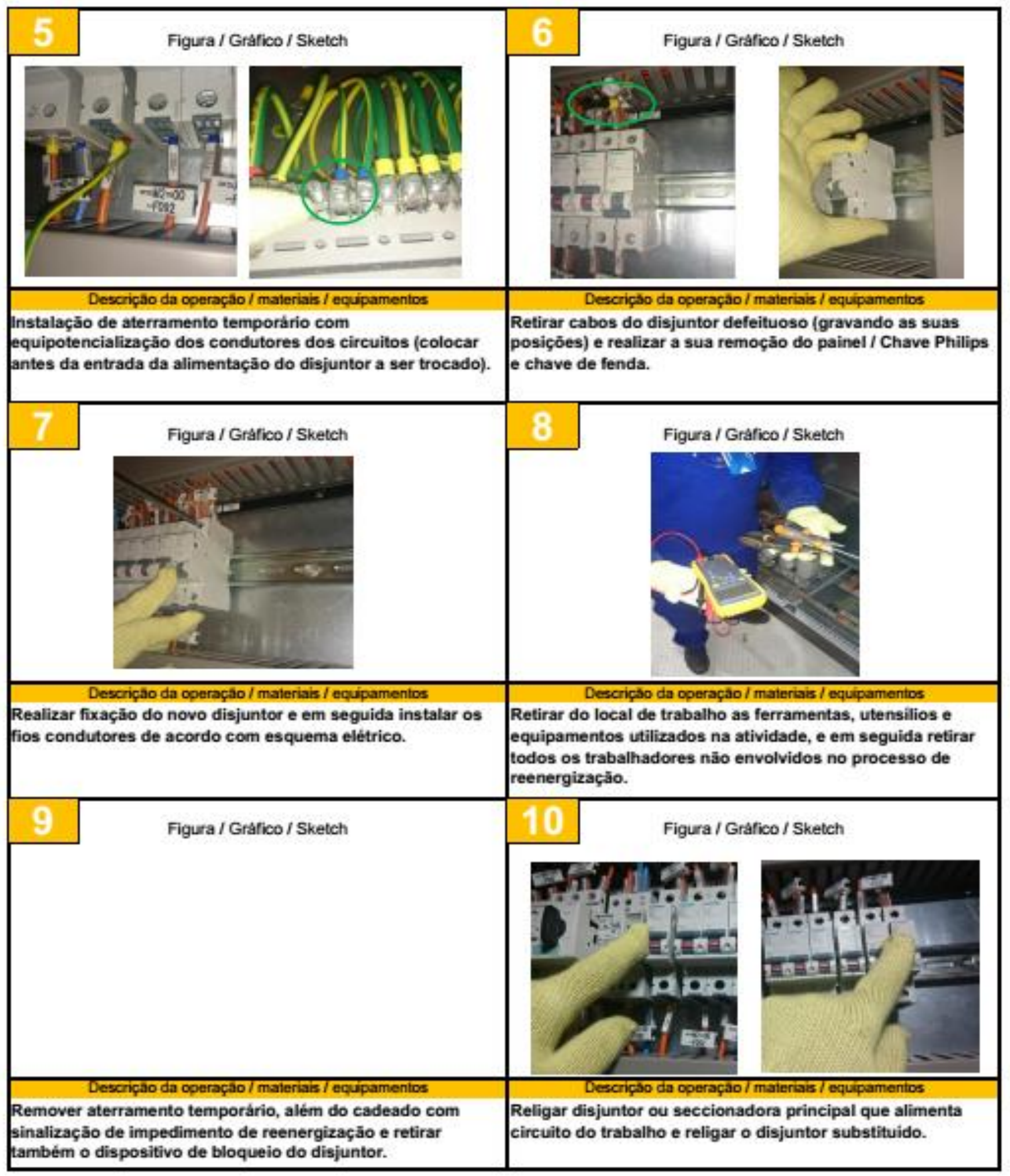

Fonte: Elaborada pelo autor, 2016. 


\section{Dados dos autores:}

Nome completo: Daniel Ferreira Fernandes de Albuquerque

Filiação Institucional: Instituto Educacional /UFMG

Departamento: Especialização em Engenharia de Segurança do Trabalho

Função ou cargo ocupado: Engenheiro eletricista e de segurança do trabalho

Endereço completo para correspondência: Rua Artur Enedino dos Anjos, 311, Apto 103, Altiplano, João Pessoa, PB, Brasil, CEP: 58046-180

Telefones para contato: (83)988959100

E-mail: daniel.albuquerque@ee.ufcg.edu.br

Nome completo: Odilon Carreiro de Almeida Neto

Filiação institucional: Instituto de Educação Superior da Paraiba - IESP

Departamento: Coordenação Geral de Pós-Graduação

Função ou cargo ocupado: Professor/Coordenador

Endereço completo para correspondência: Av. Mato Grosso, 300 - Residencial Nabor de Assis. Bairro dos Estados, João Pessoa - PB Brasil, CEP 58030 - 080

Telefones para contato: 558399909 - 9190

E-mail: odilon@iesp.edu.br

Submetido em:25-09-2016

Aceito em: 31/12/2016 